\title{
ENEB 2019: Relato da experiência de competir no Campeonato Nacional e seus efeitos no time Enactus CEFET/RJ Angra dos Reis.
}

\author{
ENEB 2019: Report on the experience of \\ competing in the National Championship and its \\ effects on the Enactus CEFET/RJ Angra dos Reis \\ Team.
}

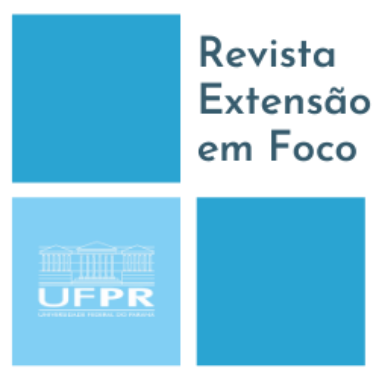

ISSN $2358-7180$

\begin{abstract}
Higor G. M. Santos ${ }^{1}$, Vanessa de Almeida Guimarães ${ }^{2}$, Elizabeth Mendes de Oliveira ${ }^{3}$, Marcus Val Springer ${ }^{4}$, Jonni Guiller Ferreira Madeira ${ }^{5}$, Bruno H. B. de Araújo ${ }^{6}$, Bruna C. O. Dias ${ }^{7}$, Maria Júlia M. de Sá ${ }^{8}$, Victória P. F. de Souza9 ${ }^{9}$ Igor O. Rodrigues ${ }^{10}$, Renato S. Ferreira ${ }^{11}$, Yasmin P. de Oliveira ${ }^{12}$
\end{abstract}

RESUMO

Este relato de extensão tem como objetivo apresentar a experiência do Time Enactus do Centro Federal de Educação Tecnológica Celso Suckow da Fonseca (CEFET/RJ) Angra dos Reis, durante a sua primeira participação como competidor principal no Evento Nacional Enactus Brasil (ENEB), o maior evento de empreendedorismo social da América Latina. Trata-se do mais importante evento do ano, em que os times participantes da rede Enactus de todas as regiões do Brasil, se encontram para trocar experiências. Além disso, cada time competidor defende os projetos desenvolvidos ao longo do ano, que têm em comum o objetivo de promover o desenvolvimento sustentável e empoderamento das comunidades em que atuam. Participar do campeonato trouxe uma nova perspectiva para o time, tanto em relação às

\footnotetext{
${ }^{1}$ Estudante de Engenharia Mecânica. CEFET/RJ, Angra dos Reis, Rio de Janeiro, Brasil. E-mail: higor.santos@aluno.cefet-rj.br. Orcid: https://orcid.org/0000-0003-3180-0054

2 Doutora em Engenharia de Transportes. CEFET/RJ, Angra dos Reis, Rio de Janeiro, Brasil. E-mail: vanessa.guimaraes@cefet-rj.br. Orcid: https://orcid.org/0000-0001-7662-3499

3 Doutora em Engenharia Metalúrgica. CEFET/RJ, Angra dos Reis, Rio de Janeiro, Brasil. E-mail: elizabeth.oliveira@cefet-rj.br. Orcid: http://orcid.org/0000-0002-9205-8570

4 Mestre em Administração. CEFET/RJ, Angra dos Reis, Rio de Janeiro, Brasil. E-mail: marcus.springer@cefet-rj.br. Orcid: https://orcid.org/0000-0003-1125-8878

${ }^{5}$ Doutor em Ciência, Tecnologia e Inovação Agropecuária. CEFET/RJ, Angra dos Reis, Rio de Janeiro, Brasil. E-mail: jonni.madeira@ cefet-rj.br. Orcid: https://orcid.org/0000-0001-5676-1720

6 Estudante de Engenharia Elétrica. CEFET/RJ, Angra dos Reis, Rio de Janeiro, Brasil. E-mail: bruno.araujo@aluno.cefet-rj.br. Orcid: https://orcid.org/0000-0001-9612-7484

7 Estudante de Engenharia Elétrica. CEFET/RJ, Angra dos Reis, Rio de Janeiro, Brasil. E-mail: bruna.dias@aluno.cefet-rj.br. Orcid: https://orcid.org/0000-0003-4338-1811

8 Estudante de Engenharia Mecânica. CEFET/RJ, Angra dos Reis, Rio de Janeiro, Brasil. E-mail: maria.marques@aluno.cefet-rj.br. Orcid: https://orcid.org/0000-0002-1764-7586

9 Estudante de Engenharia Elétrica. CEFET/RJ, Angra dos Reis, Rio de Janeiro, Brasil. E-mail: victoria.souza@aluno.cefet-rj.br. Orcid: https://orcid.org/0000-0001-9165-6707

10 Estudante de Engenharia Mecânica. CEFET/RJ, Angra dos Reis, Rio de Janeiro, Brasil. E-mail: igor.rodrigues.2@aluno.cefet-rj.br. Orcid: https://orcid.org/0000-0001-9284-1496

11 Estudante de Engenharia Mecânica. CEFET/RJ, Angra dos Reis, Rio de Janeiro, Brasil. E-mail: renato.ferreira@aluno.cefet-rj.br. Orcid: https://orcid.org/0000-0002-6552-3473

12 Estudante de Engenharia Mecânica. CEFET/RJ, Angra dos Reis, Rio de Janeiro, Brasil. E-mail: yasmin.oliveira@aluno.cefet-rj.br. Orcid: https://orcid.org/0000-0003-0474-0906
} 
possibilidades da criação de um projeto, quanto na magnitude do poder de transformação da rede por meio do impacto que o desenvolvimento desses projetos pode ter na vida dos brasileiros.

Palavras-chave: Empreendedorismo social. Inovação. Enactus.

\section{ABSTRACT}

This extension report aims to present the experience of the team Enactus Centro Federal de Educação Tecnológica Celso Suckow da Fonseca (CEFET/RJ) Angra dos Reis, during it's first participation as a main competitor in Evento Nacional Enactus Brasil (ENEB), the largest social entrepreneurship event in Latin America. This is the most important annual event where Enactus teams from all regions in Brazil meet each other to exchange experiences. Besides that, every competing team defends the projects that were developed throughout the entire year, which has as a common goal promoting the sustainable development and empowerment of the communities they act on. Participating in the championship brought a new perspective for the team, both in relation to the possibilities of creating a project as in terms of the magnitude from the transformation power caused by it's teams through the impact that the advanced development of these projects can have on Brazilian people's lives.

Keywords: Social entrepreneurship. Innovation. Enactus.

\section{INTRODUÇÃO}

Fundada em 1975 pelo advogado Robert T. Davis, em nome do Instituto Nacional de Liderança dos Estados Unidos, com o nome de Students in Free Enterprise (SIFE, ou Estudantes em Empreendimento Livre, em tradução), a Enactus é uma organização internacional sem fins lucrativos que incentiva estudantes, professores e empresas a aplicar o empreendedorismo social em 37 países, 1730 campi universitários, somando cerca de 72.000 estudantes que impactam 1,3 milhões de vidas, desenvolvendo comunidades vulneráveis ao redor do mundo (Figura 1). Inicialmente o propósito da organização era oferecer um programa de treinamento em liderança feito para estudantes universitários, para que este conhecimento pudesse ser repassado para as comunidades (Forbes, 2014). Mais tarde, esses alunos seriam avaliados em uma competição de acordo com os resultados de seus esforços na transformação dos locais que atuaram.

Quarenta e quatro anos após a sua criação, a Enactus se tornou uma rede universitária colaborativa, considerada uma das maiores plataformas de ensino experimental do mundo, que protagoniza melhorias e mudanças na qualidade de vida de milhares de pessoas por meio dos projetos desenvolvidos pelos líderes estudantis. Os times Enactus promovem a mudança em suas comunidades por meio de projetos, que mais tarde poderão ser transformados em negócios sociais, desenvolvidos em parceria entre alunos, comunidades, professores conselheiros e outros parceiros. A 
sustentabilidade é o principal pilar dos projetos Enactus, tendo em vista que o objetivo é que a comunidade possa gerir, expandir e replicar o projeto após um período de desincubação do time em relação aos beneficiários.

Em seu sentido literal, o termo 'sustentabilidade consiste na capacidade de
sustentação de um sistema. O vocábulo latim 'sustentare', do qual o termo
deriva, tem o significado de suster, suportar, conservar em bom estado, manter,
resistir. Torna-se claro, assim, o caráter intertemporal do conceito, que,
aplicado a um sistema, remete à possibilidade de que seus atributos sejam
mantidos ao longo do tempo, mesmo em face de interferências externas a ele. (BICALHO, 2016)

Todo projeto Enactus visa impactar a comunidade em que está atuando nos âmbitos social, econômico e ambiental, seguindo as diretrizes da Agenda 2030 da Organização das Nações Unidas (ONU, 2015). Reconhece-se que os projetos são feitos de pessoas e para pessoas e, portanto, cada projeto deve ser co-criado com a comunidade com a qual se está trabalhando. A comunidade tem e deve ser protagonista de todas as ações do projeto, além de ter voz ativa desde as fases mais iniciais até a sua desincubação.

Figura 1 - Países onde a rede Enactus atua

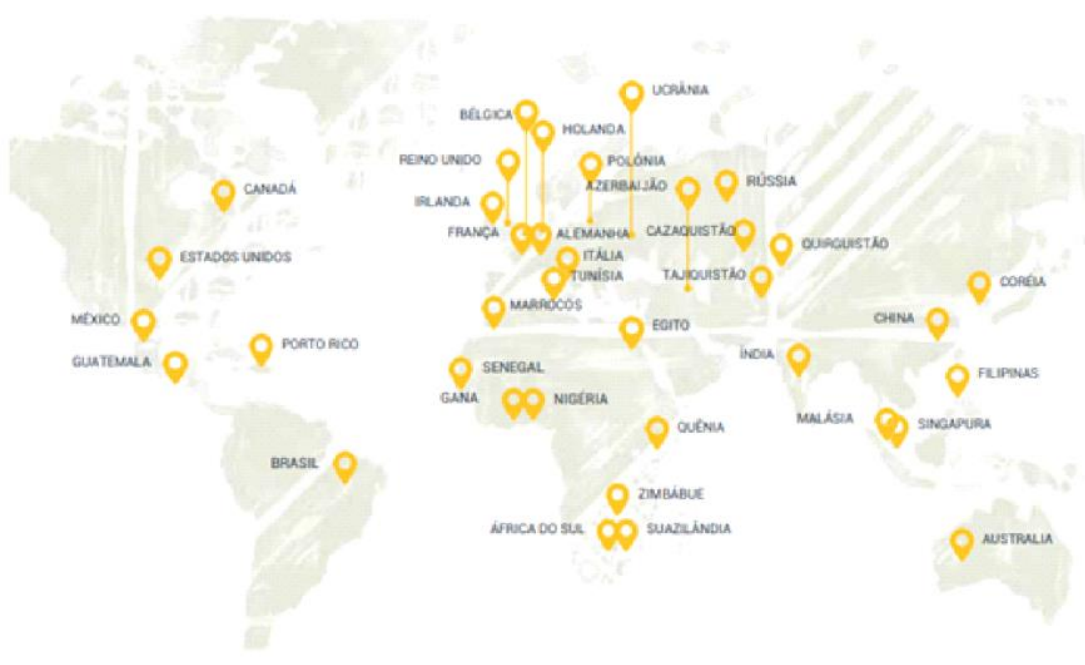

Fonte: Enactus Brasil (2019).

A rede Enactus chegou ao Brasil em 1998, tendo o CEFET/RJ como primeiro time. e, atualmente, conta com 120 times, presente em 21 estados, com cerca de 2.800 universitários ligados à rede em todo país (Enactus Brasil, 2020). Atraídos pelos valores e pela missão da Enactus, várias empresas de diferentes ramos de atuação firmaram parcerias com a organização a fim de auxiliar e investir nos projetos desenvolvidos pelos 
times do país. Suas contribuições são variadas, sendo as mais frequentes: fomento por meio de editais, webinars, conferências e eventos pontuais voltados exclusivamente para participantes rede. Além disso, há oportunidades de estágio para membros dos times. Dentre alguns parceiros, podemos citar: Fundação Lemann, Tilibra, Amanco, KPMG, Mcdonald's, Ford, Bic, Unilever, DSM, Nufarm, dentre outras.

Participante cadastrado da rede desde 2016, o time Enactus CEFET/RJ Angra dos Reis conta com 18 membros de três cursos oferecidos pela instituição: Engenharia Elétrica, Engenharia Mecânica e Engenharia Metalúrgica. Assim, este relato de extensão tem como objetivo descrever a experiência de participar pela primeira vez da liga principal do campeonato nacional, no ano de 2019. Salienta-se que neste campeonato foi apresentado o Projeto Santa Rita, fruto de um esforço conjunto entre um projeto de extensão, um projeto de iniciação científica e um grupo de pesquisa liderados pelos professores conselheiros do time (refletindo a indissociabilidade entre ensino-pesquisaextensão).

A indissociabilidade entre ensino, pesquisa e extensão caracteriza-se [...] como "um processo multifacetado de relações e de correlações que busca a unidade da teoria e da prática", pois se constitui princípio das atividades-fim da universidade. (BIMBATO 2013, p. 19)

A partir desta introdução, este relatório está dividido em 8 seções: a) descrição do evento nacional; b) descrição do projeto desenvolvido pelo time; c) preparação do time para o campeonato; d) descrição do primeiro dia do evento e das vivências participadas pelos integrantes do time, oferecidas pelas empresas parceiras da rede; e) descrição do segundo e terceiro dia de evento; f) apresentação no campeonato nacional; g) relato dos impactos que experiência teve no time; e, h) considerações finais.

\section{EVENTO NACIONAL ENACTUS BRASIL}

A Enactus Brasil faz o seu planejamento anual em ciclos, que tem fim e início no mês de julho. No fim de cada ciclo, anualmente, acontece o Evento Nacional Enactus Brasil (ENEB), um evento de empreendedorismo social, no qual os times Enactus de todo o país se reúnem por 3 dias em uma das cidades do Brasil. O evento é o principal momento de colaboração, socialização e troca de experiências entre os times. 
O conceito de empreendedorismo social está pautado na criação de valor social e na introdução de inovações de metodologia, serviços ou produtos, as quais gerariam uma transformação social. A inserção da dimensão econômica e da lógica de mercado abriu novas possibilidades para a atuação das organizações que até então contemplavam uma única dimensão (social ou econômica). Nesse sentido, surgem novos termos para caracterizar iniciativas que operam na lógica de mercado, porém com objetivos de geração de valor social: empresas sociais, negócios sociais e negócios inclusivos. (ROSOLEN, TISCOSKI, COMINI, 2014, p. 87)

Em 2019, o ENEB aconteceu na cidade de São Paulo entre os dias 17 e 19 de julho. Os membros da rede se dividiram em atividades oferecidas pela Enactus Brasil e seus parceiros, como será abordado nas Seções 2.3 e 2.4. Durante o ENEB acontece o Campeonato Nacional, competição em que vários times do país apresentam os resultados dos projetos para um júri composto por representantes de empresas parceiras da Enactus Brasil, órgãos públicos e outras organizações. O time mais bem avaliado é premiado e representa o Brasil na Enactus World Cup, que é o Campeonato Mundial da Enactus.

O primeiro dia do ENEB aconteceu na Universidade Presbiteriana Mackenzie, onde foi feito o credenciamento dos times inscritos no evento. Nesse dia foram feitas as apresentações na liga Rookie, voltada para times Enactus que nunca competiram no Campeonato Nacional. Aconteceram, também, as vivências que são excursões guiadas a empresas parceiras da Enactus Brasil, em que os times têm a oportunidade de participar das atividades oferecidas.

Os dois últimos dias do ENEB aconteceram no Expo Center Norte, um centro de convenções localizado na Zona Norte da cidade de São Paulo. Nele aconteceram as principais atividades do ENEB em auditórios espalhados no $2^{\circ}$ e $3^{\circ}$ pavilhão do espaço: o Campeonato Nacional e as palestras ministradas por convidados. O evento também contou com a presença de estandes promovidos pelas empresas parceiras, que reuniam atividades e rodas de conversa. Uma vez compreendidas as atividades do ENEB a Seção 2.1 detalha o projeto Santa Rita, que foi apresentado pelo Time CEFET/RJ Angra dos Reis na competição.

\subsection{O PROJETO SANTA RITA}

As fases de um projeto Enactus são divididas em: Insights, Implementação, Impacto e Ignição. Além disso, são feitas pré-auditorias ao longo dos ciclos com os times 
de todo o país a fim de se acompanhar o desenvolvimento dos projetos da rede. Para ser participante da liga principal, o projeto do time deve estar no mínimo na fase de implementação. Já para a participação na liga rookie, projetos em Insights (planejamento) podem ser submetidos.

Para poder participar da competição, representantes da Enactus Brasil que auditam os times devem ser informados pelos times sobre a participação na competição na sua última fase (que acontece em meados de junho), junto com o preenchimento de uma série de requisitos. Cada projeto requer seu próprio documento de auditoria, pois a mesma é focada nos projetos e suas conquistas, e não nos times.

No ano de 2019 o nosso time, Enactus CEFET/RJ Angra dos Reis, apresentou o projeto "Santa Rita", que foi desenvolvido com o Grupo de Nanociência e Meio Ambiente do CEFET/RJ Angra dos Reis para suprir as necessidades de consumo de gás da comunidade Quilombola de Santa Rita do Bracuí na cidade de Angra dos Reis. Destacase neste ponto a indissociabilidade entre o ensino, a pesquisa e a extensão, tendo em vista que este projeto foi desenvolvido como projeto de extensão, com bolsa financiada pelo CEFET/RJ e contou com apoio de professores pesquisadores, aplicando conhecimentos adquiridos em sala de aula e em pesquisas extraclasse.

A ideia do "Santa Rita" estava alinhada com um projeto de iniciação científica de um dos nossos professores conselheiros, que tinha como objetivo estudar a eficiência do uso da manipueira na produção de biogás. Assim, a produção do biogás seria feita por meio de um biodigestor, que corresponde a uma unidade de aceleração da decomposição de matéria orgânica na ausência de oxigênio, e possui como resultado do processo a produção de biogás e biofertilizantes.

O modelo de biodigestor desenvolvido no Projeto Santa Rita foi criado a partir de uma patente e modelo do professor Vinicius Oliveira de Araújo da Universidade Federal Fluminense. A proposta da produção de biogás a partir da manipueira tem relação com a vocação da comunidade quilombola assistida pelo projeto (Figura 2). Dentro da comunidade de Santa Rita existe a cultura da produção de farinha de mandioca por parte dos moradores. Durante o processo de prensagem e produção da farinha, tem-se como resíduo a manipueira: "um líquido branco, tóxico, que contém ácido cianídrico, sendo até 25 vezes mais poluente que o esgoto" (DOS SANTOS et al., 2012, p. 263). Antes do 
desenvolvimento do projeto, a manipueira era indevidamente descartada na natureza, sob o risco de contaminar plantações, rios e até o lençol freático da comunidade.

Figura 2 - Entrega do primeiro protótipo do biodigestor para a comunidade de Santa Rita

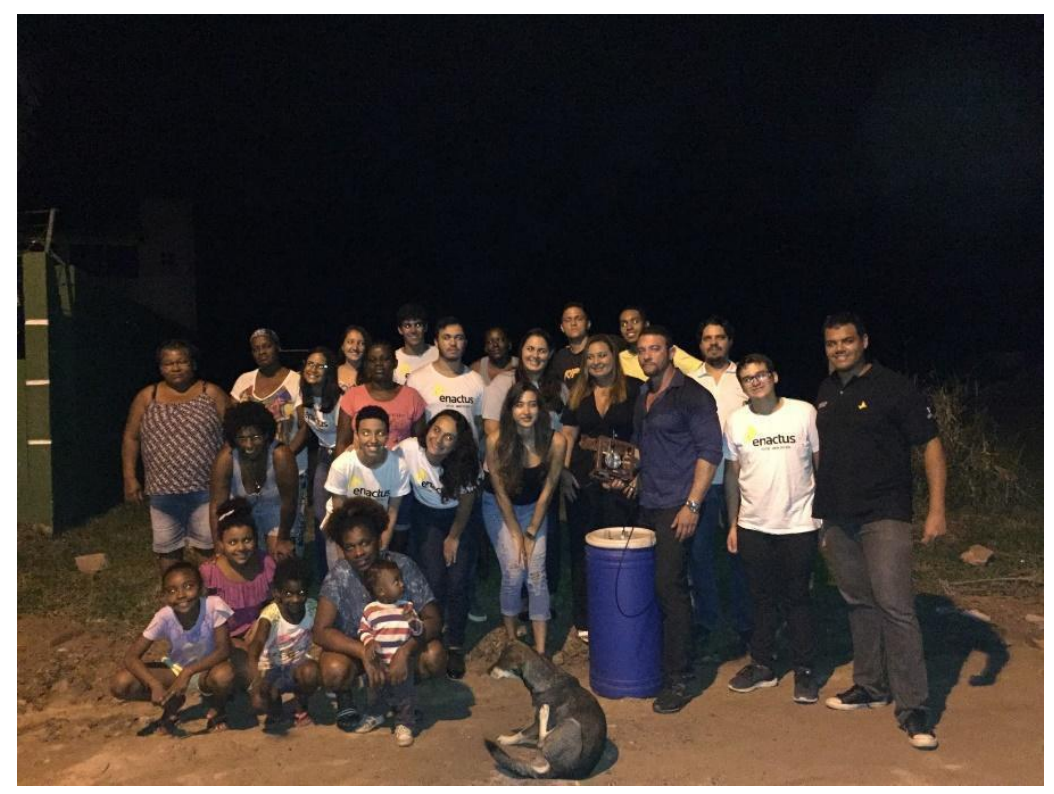

Fonte: Enactus CEFET/RJ Angra dos Reis (2018).

Assim, o projeto Santa Rita foi construído com o intuito de transformar a vida da comunidade, tanto financeiramente quanto ambientalmente e socialmente em consonância com o conceito de desenvolvimento sustentável. De acordo com Camargo (2003, p. 43) em essência, o desenvolvimento sustentável é um processo de transformação no qual a exploração dos recursos, a direção dos investimentos, a orientação do desenvolvimento tecnológico e a mudança institucional se harmonizam e reforçam o potencial presente e futuro, a fim de atender às necessidades e aspirações humanas.

Os biodigestores construídos seriam de uma única fase, compactos e de baixo custo em relação aos demais disponíveis no mercado, conforme evidenciado por Guiller et al. (2019, p.202):

O biodigestor construído era um digestor de fluxo descontínuo (reator de estágio único). Cada batela do biodigestor foi composta para apenas um recipiente: a câmara de digestão (de 70 litros), volume líquido do digestor (60 litros), os 10 litros restantes acumulam o gás, funcionando como um gastômetro. [...] Na tampa da câmara de digestão foi instalado um cano de cobre no tubo da válvula de gás de borracha (saída do biogás), esse cano conecta a câmara de digestão à boca do fogão. O fogão de acampamento foi adaptado porque o buraco da saída de gás tem menos de $1 \mathrm{~mm}$ de diâmetro, o 
que não permite o fluxo do biogás, já que ele é de baixa pressão. Dessa maneira, o buraco foi alargado para $5 \mathrm{~mm}$ de diâmetro, permitindo o fluxo de gás de forma eficiente.

Assim, conforme a farinha de mandioca fosse sendo produzida e a manipueira gerada, os biodigestores seriam enchidos para que, após um mês, pudesse iniciar a produção de biogás. Este biogás seria utilizado na própria comunidade: ao ser produzido, ele seria encanado e revertido a casa dos beneficiários do projeto, inicialmente para cozimentos simples. A ideia era proporcionar economia às famílias em relação ao gasto do botijão de gás tradicional e, ao mesmo tempo, reduzir a degradação do meio ambiente da comunidade causada pelo descarte indevido de manipueira. Salienta-se que este impacto ambiental ainda tinha um potencial danoso maior uma vez que muitos moradores também se ocupam também de agricultura.

Tendo em vista o âmbito econômico, o projeto tinha como objetivo a venda do biofertilizante produzido pelo biodigestor, que possui alta quantidade de nitrogênio, o que o faz ser altamente valorizado no mercado. Com isso, os beneficiários não precisariam mais comprar gás de cozinha e ainda impulsionariam as plantações do local com o uso do biofertilizante produzido. A venda levaria visibilidade para a comunidade com a marca do Quilombo, gerando benefícios como o aumento de circulação de turistas no local e a facilitação da venda dos alimentos produzidos inteiramente na comunidade. Por ser um resíduo tóxico, o descarte da manipueira no biodigestor reduz a poluição do solo e rios da comunidade que, neste momento, teria uma destinação mais sustentável e limpa.

A partir do escalonamento do projeto, a produção de manipueira iria crescer e, dessa maneira, aumentar a produção dos biodigestores até que eles pudessem substituir totalmente o botijão de gás convencional. Uma segunda etapa pensada para o projeto era a criação de uma cooperativa da comunidade para a produção e venda de farinha de mandioca sobressalente, com o selo de produtores orgânicos do SEBRAE.

Salienta-se que até julho de 2019, quando apresentamos o projeto no ENEB, este estava em fase de prototipação e testes junto à comunidade. O protótipo de biodigestor havia sido entregue, mas até o campeonato, nenhuma vida foi diretamente impactada pelas ações do biodigestor.

\subsection{PREPARAÇÃO PARA O CAMPEONATO}


Apesar do ENEB ter acontecido no mês de julho/2019, a preparação do time Enactus CEFET/RJ Angra dos Reis iniciou no começo do ano de 2019. Dada a importância da competição e da quantidade de times inscritos, a preparação do texto e seus ensaios começam em meados de março com a definição do "time de apresentação". Pelas regras da competição são permitidos, no máximo, seis apresentadores por time, além de um membro extra que participará da apresentação. Este é o responsável pela parte técnica, controlando a passagem de slides, regulando o som dos vídeos etc.

Para definição do time de apresentação foram feitas rodas de conversa e sondagem com os membros a fim de identificar os interessados e indicar a formação final do grupo. Uma vez formado o grupo, foram realizadas atividades de capacitação e de ensaio da apresentação visando preparar ao máximo os membros para o campeonato. Simultaneamente, foram criadas as primeiras versões do texto de apresentação. " $A$ criação deste texto é um desafio a mais, pois cada time tem apenas 17 minutos para apresentar a equipe, o contexto do projeto, suas atividades, público-alvo, progresso e futuros planos” (Enactus Brasil, 2019).

Pelo fato de o projeto estar em andamento enquanto são realizadas a criação do texto de apresentação, muitas das informações que serão apresentadas como indicadores e status de progresso foram deixadas em aberto e incluídas em data próxima da competição, para que assim, pudéssemos ter dados mais atualizados.

Além do texto de apresentação, é obrigatório a criação de um relatório anual do projeto (com um resumo visual dos seus principais pontos), que é entregue antecipadamente aos jurados da competição. Após enviar estes documentos à Enactus Brasil, inclusive o texto de apresentação, não é permitido que o time adicione informações além das que já foram previamente auditadas.

\subsection{PRIMEIRO DIA DE ENEB: VIVÊNCIAS ENACTOR}

As Vivências Enactor consistiram em visitas guiadas preparadas pelos parceiros da Enactus Brasil, onde os membros de vários times visitaram espaços e as próprias empresas parceiras, tais como: Organização das Nações Unidas (ONU), Aliança Empreendedora, Fábrica de Criatividade, RedBull, Folha de S. Paulo, Fundação Estudar, 
McDonald's, YouGreen, entre outras. Os membros do nosso time Enactus participaram as atividades da Fábrica de Criatividade e da ONU, cujo relato pode ser lido a seguir.

\subsubsection{Fábrica de Criatividade}

Com sede no distrito de Capão Redondo - São Paulo, que já foi considerado pelas Nações Unidas o distrito mais perigoso do mundo, a Fábrica de Criatividade se ergue como um farol em meio à escuridão. Criada do resultado de uma tragédia familiar, medo e de um sentimento de revolta com a situação enfrentada no lugar onde morava, Denilson Shikako, atual Diretor Presidente da empresa, criou a fábrica com o objetivo de despertar a criatividade e trazer oportunidades para mentes criativas locais da periferia de São Paulo, oferecendo um ambiente em que eles pudessem crescer e se desenvolver.

Sendo um dos primeiros colaboradores e parceiros da Enactus Brasil, a fábrica realizou com os estudantes selecionados um tour guiado por dois de seus funcionários pela sede da organização. Durante o tour foram mostrados os atuais projetos em que a empresa está trabalhando e foi revelada uma de suas metodologias de pensamento criativo. Além disso, foi contada a história por trás da concepção da empresa - que o time considera fascinante e inspiradora - e como eles usam da criatividade para impulsionar e transformar a vida de inúmeras pessoas que têm aulas no prédio e que participam de seus projetos ou de suas consultorias.

\subsubsection{ONU}

Na Vivência Enactor da ONU Brasil, o time pôde experienciar grandes momentos de reflexão sobre o compromisso que cada indivíduo tem como habitante do nosso planeta. O time foi convidado a refletir sobre os pequenos atos diários que podem auxiliar na preservação do meio ambiente, além de discutir sobre as ações constantes de transformação que podem salvar este planeta que chamamos de casa. Apresentando o significado da Agenda 2030 (ONU, 2020) e sua importância, as integrantes da ONU nos trouxeram a urgente percepção de que precisamos estar atentos e perseverantes em compactuar com os 17 Objetivos de Desenvolvimento Sustentáveis (ODS).

"Todos os dias do evento trazem uma gama de conhecimento. São três dias de muita experiência, inovação e o principal: emoção." (Time Enactus CEFET/RJ Angra dos Reis, 2019) 


\subsection{SEGUNDO E TERCEIRO DIAS DE ENEB: ATIVIDADES NO EXPO CENTER NORTE E APRESENTAÇÃO NO CAMPEONATO}

Os dois primeiros andares do centro de convenções foram totalmente decorados e preparados para várias atrações que aconteceram simultaneamente, em conjunto com os vários auditórios para apresentações e eventos individuais, além de um grande auditório principal. As atrações variam de estandes montados por empresas parceiras à Enactus Mall.

A Enactus Mall consiste em um espaço físico que a Enactus Brasil fornece para que os times possam comercializar itens e materiais relacionados a seus estados de origem e seus projetos. Além de ser uma ótima oportunidade para conhecer outras culturas, a Enactus Mall é um dos principais espaços para os times divulgarem seus projetos e os produtos diretos advindos deles. Nos estandes das empresas, por sua vez, aconteciam eventos pontuais, rodas de conversas, entregas de brindes e, principalmente, a apresentação institucional para os participantes (Figura 3).

No início do segundo dia de evento, no auditório principal foram apresentados todos os times que estavam participando do ENEB. Além disso, foram feitas apresentações dos convidados, depoimentos de professores e representantes de comunidades empoderadas por projetos de times Enactus e a entrega dos prêmios ODS. Esta premiação tem como foco os 17 ODS traçados pelas Nações Unidas em setembro de 2015 para a Agenda 2030, que consiste em "um plano de ação para as pessoas, para o planeta e para a prosperidade. Ela também busca fortalecer a paz. universal com mais liberdade." (Nações Unidas, 2015). Assim, foram premiados 17 projetos Enactus que causaram impactos positivos na rede brasileira e estavam associados às metas e desafios de um ODS específico.

Figura 3 - O time participando de uma ação no estande da Unilever no $2^{\circ}$ dia de evento. 


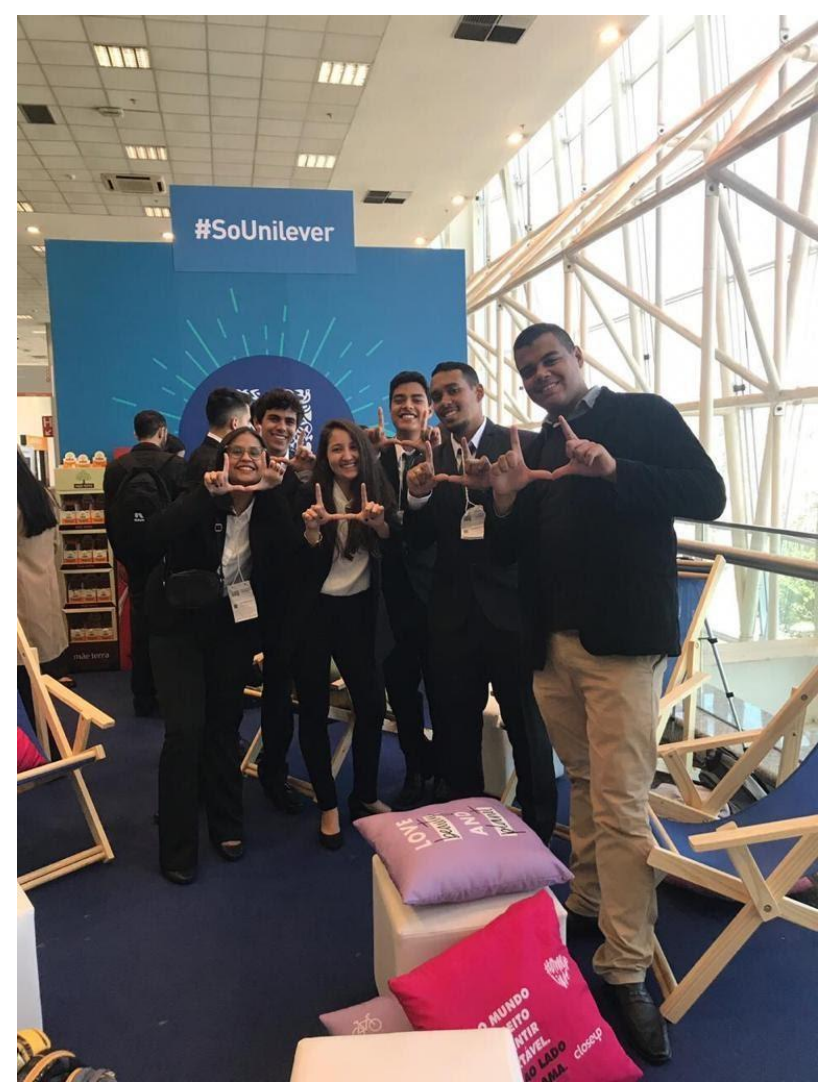

Fonte: Enactus CEFET/RJ Angra dos Reis (2019).

Além disso, durante os dias aconteceu o campeonato nacional: principal razão da presença da maioria dos times, incluindo o nosso. "O campeonato é a culminação de mais de um ano de trabalho e planejamento intenso. Nossa razão de alegria, mas ao mesmo tempo de bastante nervosismo, o Campeonato Nacional." (Enactus CEFET Angra, 2019)

\subsubsection{APRESENTAÇÃO NO CAMPEONATO NACIONAL}

A Enactus acredita que a competição, quando exercitada de forma saudável, é uma maneira de inspirar e de estimular a inovação e a criação de projetos de maior impacto para as comunidades. Desse modo, a rede realiza anualmente a Enactus World Cup, o Campeonato Mundial. Nele competem com um time representante de um dos 37 países no qual a rede está presente.

Para escolher o seu representante, a Enactus Brasil realiza, durante o ENEB, o Campeonato Nacional, que é tido como uma experiência essencial de um membro Enactus. A competição é dividida em duas ligas de competição: rookie e principal. 
A liga rookie (novato, em inglês), como o próprio nome sugere, é destinada a times que estão competindo pela primeira vez no campeonato. Cada time só pode se apresentar na liga rookie uma vez, pois é voltada para times com um ano ou menos de criação. Assim, na edição de 2019 apenas 15 times participaram desta modalidade. O nosso time estreou na competição em 2018 na liga Rookie, quando o nosso projeto era apenas um conceito. No entanto, embora o projeto ainda não estivesse plenamente executado, como evidenciado na Seção 2.1, por força de regra, nos apresentamos na liga principal em 2019.

A liga principal é a parte mais importante da competição e do ENEB: "Além de ser um momento de grande nervosismo para os times que irão se apresentar, é um dos principais momentos de orgulho, pois é onde podemos apresentar o fruto do trabalho e colaboração de toda a equipe, o resultado do esforço de várias pessoas ao longo dos anos. É um momento em que não apenas podemos compartilhar os nossos projetos e paixões, mas também a história de suas comunidades, além de dar visibilidade e empoderamento a pessoas que muitas vezes não recebem devida atenção" (Enactus CEFET Angra, 2019).

Todas as apresentações são abertas ao público (inclusive aos competidores), no entanto há limite de vagas nos auditórios, a fim de evitar aglomerações que atrapalhem o time em apresentação. A competição principal se estende pelos dois últimos dias do evento: no primeiro, todos os competidores (48 times, no ano de 2019) apresentam seus projetos na rodada de abertura; no segundo dia acontecem a apresentação dos 16 times classificados no dia anterior para a semifinal e, após o almoço, acontece a rodada final com os 4 times finalistas e a entrega do prêmio principal.

No segundo dia, são organizadas as rodadas de apresentação: os times são separados por grupos (num sistema de chaveamento), onde cada grupo tem o seu próprio auditório para realizar as suas apresentações. Cada time dispõe de 5 minutos de acesso ao auditório para checar seus equipamentos de som e computadores. "Esse momento é visto como uns dos mais cruciais da competição, pois momentos de falha de sincronização de som ou falha de imagem podem custar caro aos times. Portanto cada minuto deve ser aproveitado ao máximo.” (Time Enactus Angra dos Reis, 2019).

A KPMG realiza a auditoria oficial da competição e a bancada de jurados é composta por representantes das empresas parceiras da Enactus Brasil. Ao final de cada rodada, por conta da troca de jurados que os avaliam, cada time recebe de seus jurados 
uma folha preenchida com feedback. Nela os jurados devolvem aos times as críticas construtivas que fizeram aos seus projetos, evidenciando os pontos que poderiam ser modificados e aprimorados.

Embora o time não tenha passado pela primeira rodada, os integrantes fizeram questão de assistir às semifinais (que eram simultâneas) e à grande final a fim de observar pontos de melhorias para futuras apresentações e campeonatos.

\subsection{IMPACTOS DA EXPERIÊNCIA PARA OS MEMBROS DO TIME}

Embora o projeto no time não tenha se classificado para as semifinais, a participação no ENEB foi transformadora para os membros do Time Enactus Angra dos Reis (Figura 4). No Quadro 1 estão listadas as impressões e resultados da experiência para cada um dos membros que participou do evento.

Quadro 1 - Impressões e resultados da experiência do time em participar do ENEB

\begin{tabular}{|l|l|}
\hline Membro & Relato da experiência \\
\hline Bruna Dias & "Bom, eu não fui apresentadora no ENEB, mas minha experiência foi \\
incrível. Consegui sentir na pele o que os apresentadores sentiram contando \\
nossa história para tantas pessoas. Nunca imaginei fortalecer tanto a minha \\
amizade com o meu próprio time, mas durante aquela experiência nos \\
tornamos praticamente um só. Era uma paixão gigante, todo mundo junto por \\
um único propósito. Também conheci algumas pessoas de outros times que \\
me fizeram olhar a rede com olhos ainda mais encantados. Assisti a cada \\
apresentação afundada em lágrimas. É lindo ver como a rede se preocupa \\
com as pessoas, com o mundo! E foi maravilhoso fazer parte disso. Levo \\
comigo todos os dias os ensinamentos que o ENEB me proporcionou, tanto \\
pessoais quanto profissionais, e também agradeço eternamente pela \\
oportunidade que o Time Enactus CEFET/RJ Angra dos Reis me deu de fazer \\
parte de algo tão maravilhoso!"
\end{tabular}




\begin{tabular}{|c|c|}
\hline & $\begin{array}{l}\text { rcado, teremos de desenvolver projetos e defender a realização deles } \\
\text { ante os financiadores." }\end{array}$ \\
\hline $\begin{array}{l}\text { Higor } \\
\text { Gonçalves } \\
(2019)\end{array}$ & $\begin{array}{l}\text { "É difícil e talvez impossível conseguir traduzir em palavras o sentimento da } \\
\text { experiência que passamos. Eu sempre tive uma ansiedade e dificuldade para } \\
\text { apresentar qualquer coisa, até trabalhos de faculdade, então apresentar o } \\
\text { trabalho de todo um ano a representantes de grandes empresas é algo que } \\
\text { seria impensável para mim fazer em outros tempos. Foi sem dúvidas um dos } \\
\text { momentos mais desafiadores e recompensantes da minha vida. A alegria, a } \\
\text { satisfação e o sentimento de orgulho que temos ao final do ciclo sobre todo } \\
\text { o trabalho duro que realizamos é sem explicação. Eu tenho muito orgulho da } \\
\text { rede, deste time e mal posso esperar para o que o futuro nos reserva." }\end{array}$ \\
\hline $\begin{array}{l}\text { Igor } \\
\text { Oliveira } \\
(2019)\end{array}$ & $\begin{array}{l}\text { O Campeonato me trouxe uma experiência, motivação e aprendizado } \\
\text { enormes! O evento reúne diversas pessoas de lugares diferentes, sendo a } \\
\text { maioria universitários, e isso traz uma oportunidade enorme de realizar troca } \\
\text { de informações, tanto para o time Enactus quando para a vida pessoal e } \\
\text { profissional de cada um; Com as apresentações dos outros time, aprendi } \\
\text { sobre os impactos causados por cada projeto e os formatos de apresentação; } \\
\text { Além de conhecer iniciativas que apoiam e realizam mudanças em todo o } \\
\text { Brasil e até no mundo! A ansiedade e o nervosismo pré-apresentação tomam } \\
\text { conta, mas ao mesmo tempo são sentimentos muito bons, pois através da } \\
\text { nossa imagem podemos representar nossa faculdade, comunidade e projeto. } \\
\text { A presença de jurados importantes gera a sensação de que aquele é um passo } \\
\text { muito grande na sua vida, é uma experiência inesquecível! Após a } \\
\text { apresentação o sentimento é de dever comprido. Sentimos com clareza que } \\
\text { só estamos ali por causa dos nossos beneficiados, o que faz crescer nossa } \\
\text { empatia e vontade de transformar vidas! Adquiri diversos aprendizados ao } \\
\text { ver apresentações de outros times e com as trocas de informações e contatos } \\
\text { no decorrer do campeonato. Isso gerou insights incríveis sobre os processos } \\
\text { que poderíamos realizar no nosso time e nos projetos. Ver tanta gente } \\
\text { engajada em prol de impactar vidas de forma sustentável torna o ambiente } \\
\text { extremamente agradável, o que nos deixa com um sorriso muito feliz no } \\
\text { rosto! }\end{array}$ \\
\hline $\begin{array}{l}\text { Maria Júlia } \\
\text { Marques } \\
(2019)\end{array}$ & $\begin{array}{l}\text { "Apresentar foi assustadoramente realizador. Estar naquele palco para } \\
\text { discursar tudo que havia treinado por tantos dias e sentir a pressão de } \\
\text { estarmos em frente a juízes tão importantes no âmbito dos negócios sociais é } \\
\text { uma experiência inesquecível. Nós costumamos brincar que depois de passar }\end{array}$ \\
\hline
\end{tabular}




\begin{tabular}{|c|c|}
\hline & $\begin{array}{l}\text { por uma apresentação no ENEB os seminários acadêmicos até parecem algo } \\
\text { fácil.” }\end{array}$ \\
\hline $\begin{array}{l}\text { Renato } \\
\text { Ferreira (2019) }\end{array}$ & $\begin{array}{l}\text { "A sensação de apresentar é única e é uma experiência que julguei } \\
\text { importantíssima na minha vida acadêmica, pois depois disso perdi totalmente } \\
\text { o medo de qualquer aparição em público! O ENEB é sem dúvida nenhuma } \\
\text { um evento de muita alegria e emoção, ver pessoas sendo ajudadas e se } \\
\text { ajudando é muito gratificante e traz um pouco a mais de fé na humanidade! } \\
\text { Com essa atmosfera e essa comunidade, é um evento que sempre que puder, } \\
\text { acompanharei." }\end{array}$ \\
\hline $\begin{array}{l}\text { Victória } \\
\text { Freitas (2019) }\end{array}$ & $\begin{array}{l}\text { "O ENEB é com certeza uma experiência única, sim, o que eu senti naquela } \\
\text { atmosfera eu não senti em nenhum outro lugar! Um misto de } \\
\text { responsabilidade e ao mesmo tempo felicidade de estar representando a } \\
\text { história tão linda da comunidade quilombola de Santa Rita do Bracuí. Foi um } \\
\text { momento que de longe marcou minha vida profissional e pessoal pra sempre! } \\
\text { Tenho muito orgulho da história que fizemos e esse é só o começo!” }\end{array}$ \\
\hline $\begin{array}{l}\text { Yasmin } \\
\text { Oliveira } \\
(2019)\end{array}$ & $\begin{array}{l}\text { "Posso dizer que ver o time se apresentando no ENEB foi uma experiência } \\
\text { mais surreal do que o esperado. Estávamos presentes nos ensaios, vimos os } \\
\text { vídeos das outras equipes e nos preparamos para levar a história do nosso } \\
\text { trabalho, mas não dá para imaginar o turbilhão de emoções que acaba por } \\
\text { ficar conosco para toda a vida. Assim como ver o trabalho das outras equipes, } \\
\text { sentir que todos estão ali pelo mesmo propósito, gera uma sintonia entre as } \\
\text { pessoas presentes. É difícil pensar em uma experiência de vida mais incrível } \\
\text { que essa." }\end{array}$ \\
\hline
\end{tabular}

Fonte: Time Enactus CEFET/RJ Angra dos Reis.

Figura 4 - Time posando no pavilhão do Expo Center Norte durante o último dia do evento. 


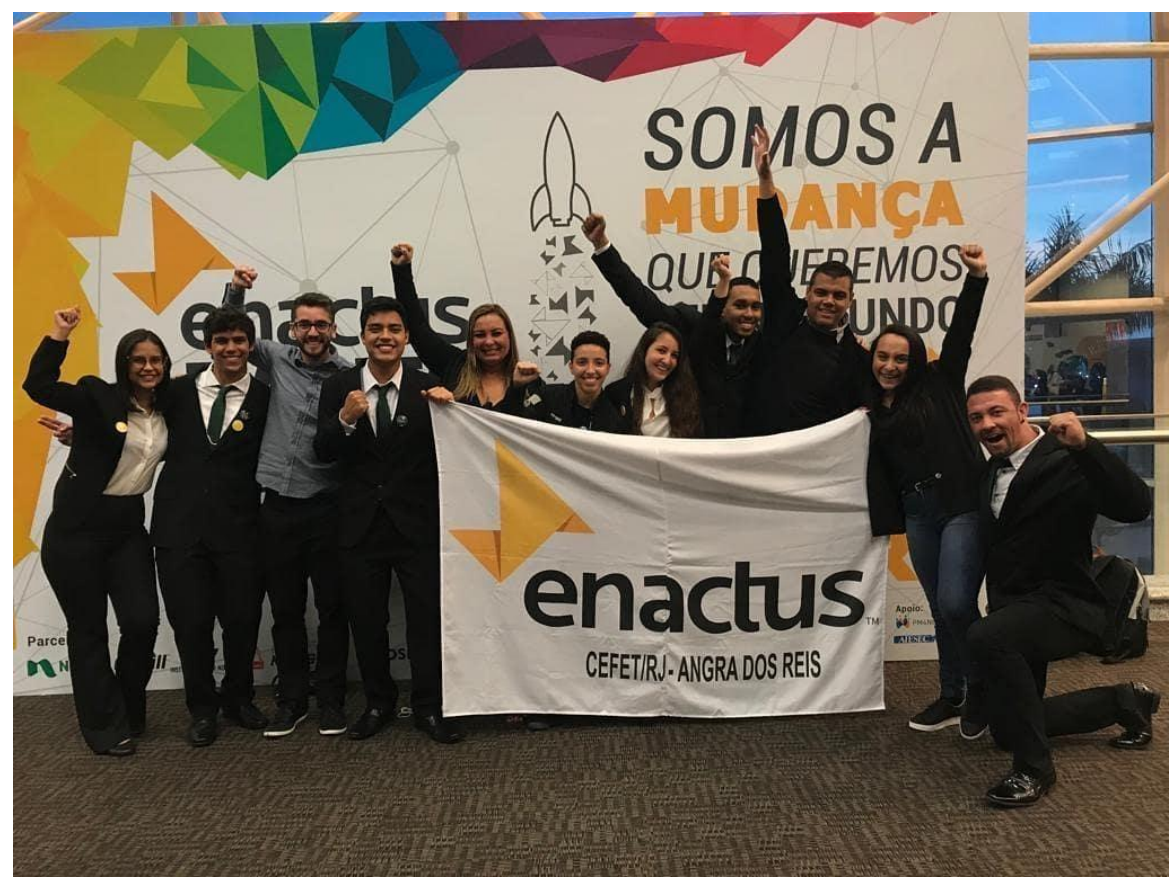

Fonte: Enactus CEFET/RJ Angra dos Reis (2019).

\section{CONSIDERAÇÕES FINAIS}

A Enactus, como rede, além de impactar e transformar a vida de milhões de pessoas a quem seus projetos são voltados, também impacta a vida de milhares de alunos que a compõem. O conhecimento e experiência profissional e interpessoal adquiridos ao longo do tempo participando da rede e criando projetos são imensuráveis, somados com a experiência e conexões formadas entre os membros do time e as comunidades impactadas. É, portanto, inspirador e recompensador fazer parte de uma comunidade mundial de jovens e professores dedicados a usar os seus conhecimentos adquiridos ao longo da vida para melhorar a vida da comunidade em que estão inseridos.

No que diz respeito ao projeto Santa Rita e ao nosso desempenho no Campeonato Nacional, não conseguimos ir além da fase inicial, chamada rodada de abertura, em razão da falta de tempo hábil para produzir resultados concretos de impacto positivo no Projeto Santa Rita, que ainda estava em fase de implementação.

Meses após o começo da implementação do projeto na comunidade e de nossa participação no ENEB, foi-se observado que a implementação do biodigestor não estava oferecendo na comunidade um impacto que se espera de um projeto Enactus, por conta da baixa produção de biogás pelo biodigestor, que ocorreu devido ao volume insuficiente 
de produção de farinha de mandioca dentro da comunidade. Isso fez o projeto ser descontinuado pelo time em setembro de 2019, porém novos projetos estão sendo criados e os feedbacks dos jurados estão sendo levados em conta durante todo o seu desenvolvimento.

Apesar de nosso resultado na competição não ser sido satisfatório, a experiência e seu impacto no time foram muito positivos, quando se reflete sobre aprendizados adquiridos durante a competição. Além disso, o feedback feito pelos jurados permitiu compreender que nosso maior ponto fraco estava associado à ausência de uma base de dados sobre a comunidade com a qual co-criamos o projeto, além da pouca maturidade na parte técnica da gestão e criação de projetos.

Tangente a apresentação, o Time Enactus Angra dos Reis considera que "o nervosismo por estar apresentando pela primeira vez na liga principal com certeza foi um fator determinante no desempenho que tivemos durante o campeonato. Já na parte técnica, observamos que uma apresentação coordenada por um vídeo concede um desempenho mais fluido e dinâmico, em vez de uma apresentação por slides".

Com todas as atividades desenvolvidas durante o ciclo 2018-2019 e a apresentação do nosso projeto no ENEB, pôde-se perceber que o time retornou para o novo ciclo ainda mais engajado, onde esperamos assim empoderar ainda mais pessoas, começando pelo próprio campus do CEFET/RJ - Angra dos Reis. Ter a chance de participar e competir no evento foi sem dúvidas uma experiência inesquecível e um divisor de águas a todos os membros do time. Por fim, com base na boa relação dos alunos e professores do campus com a Enactus ao decorrer do ano, pudemos perceber que, cada vez mais, conquistamos um espaço no coração de cada universitário e funcionário do CEFET/RJ Angra dos Reis. Sabemos que estamos fazendo a diferença, mudando nossas vidas, as vidas de pessoas que estão ao nosso lado e, principalmente, a vida de comunidades de Angra dos Reis.

\section{AGRADECIMENTOS}

Os autores agradecem ao CEFET/RJ pela bolsa de extensão concedida.

\section{REFERÊNCIAS}


BICALHO, F. Afinal, o que é sustentabilidade? 2016. Disponível em: https://blog.waycarbon.com/2016/03/o-que-e-sustentabilidade/, acesso em 06 de setembro de 2020.

BRSCAN, I. M. Manipueira, um líquido precioso. 2011. Disponível em: https://www.embrapa.br/busca-de-noticias/-/noticia/18147209/manipueira-um-liquidoprecioso\#: : text=Devido a isso $\% 2 \mathrm{C}$ muitos produtores,também desperdiçando um líquido precioso., acesso em: 06 de setembro de 2020.

CAMARGO, A. Governança para o século 21. In: TRIGUEIRO, A. Meio Ambiente no século 21: 21 especialistas falam da questão ambiental nas suas áreas de conhecimento. Rio de Janeiro: Sextante, 2003.

CÉSAR, S. B. A indissociabilidade ensino, pesquisa, extensão e a gestão do conhecimento: Estudo em universidade brasileira. Projetos, Dissertações e Teses em Sistemas de Informação e Gestão do conhecimento, Belo Horizonte. 2013. Disponível em: http://fumec.br/revistas/sigc/article/view/1918/1226, acesso em 05 de setembro de 2020 .

DOS SANTOS, G. P.; REGO, N. A. C.; DOS SANTOS, J. W. B.; JÚNIOR, F. D.; JÚNIOR; M. F. S.; Avaliação espaço-temporal dos parâmetros de qualidade da água do rio Santa Rita (BA) em função do lançamento de manipueira. Revista Ambiente \& Água - An Interdisciplinary Journal of Applied Science, v. 7, n. 3, p. 261- 278, 2012.

ENACTUS. "Manual da Competição Enactus Evento Nacional, 2019. Disponível em: $\quad$ http://brazil.enactusglobal.org/wpcontent/uploads/sites/2/2019/05/Manual-Competição-2019-vfinal.pdf, acesso em 10 de setembro de 2020 .

ENACTUS. Manual dos times - Ciclo 2019 - 2020. Relatório, 2019. Disponível em: $\quad$ http://brazil.enactusglobal.org/wp-content/uploads/sites/2/2019/11/Manual-dosTimes-2020-1.pdf, acesso em 11 de março de 2020.

ENACTUS. Our Story. 2020. Disponível em: https://enactus.org/who-we-are/ourstory/, acesso em 11 de março de 2020.

ENACTUS BRASIL. Página Inicial - Enactus Brasil. 2020. Disponível em: http://www.enactus.org.br/, acesso em 11 de março de 2020. 
FLYNN, K. Students Don't Have To Drop Out To Thrive As Social Entrepreneurs. Fobes, 2014. Disponível em: https://www.forbes.com/sites/kerryflynn/2014/08/13/students-dont-have-to-drop-out-tothrive-as-social-entrepreneurs/\#4f24a88f78f7, acesso em 19 de junho de 2020.

MADEIRA, J. G. F.; OLIVEIRA, E. M.; GUIMARÃES, V. A.; ARAÚJO, V. O.; SPRINGER, M. V.; CABRAL, H. L.; MELGAÇO, H. S.; CHAVES, Y. A. O.; NETO, A. R. F. Electricity Generation from Biogas of Cassava using Cattle Manure as inoculum: An Assessment of Potential in the Quilombola Community (Brazil). International Journal of Advanced Engineering Research and Science, v. 6, n. 6, p. 200-205, 2019.

ORGANIZAÇÃO DAS NAÇÕES UNIDAS. Transformando Nosso Mundo: A Agenda 2030 para o Desenvolvimento Sustentável. 2015. Disponível em: https://nacoesunidas.org/pos2015/agenda2030/, acesso em: 06 de setembro de 2020.

ROSOLEN, T.; TISCOSKI, G. P.; COMINI, G. M. Empreendedorismo Social e Negócios Sociais: Um Estudo Bibliométrico da Publicação Nacional e Internacional. 2014. Disponível em: https://portalseer.ufba.br/index.php/rigs/article/view/8994, acesso em 06 de setembro de 2020.

Recebido em: 19 de junho de 2020.

Aceito em: 23 de outubro de 2020. 